\title{
Políticas de obliteração do ensino de filosofia: uma narrativa sobre escombros filosóficos ${ }^{1}$
}

\author{
Philosophy teaching obliteration policies: \\ a narrative about philosophical rubble
}

\author{
Ester Maria Dreher Heuser \\ Professora doutora da Universidade Estadual do Oeste do Paraná, Toledo, PR, \\ Brasil. \\ esterheu@hotmail.com - http://orcid.org/0000-0002-1762-7526
}

Recebido em 31 de agosto de 2021

Aprovado em 24 de outubro de 2021

Publicado em 30 de dezembro de 2021

RESUMO: A partir da figura do narrador e do tipo de narrador camponês, aquele que viu a história da sua terra e a narra, criados por Walter Benjamin, o artigo apresenta-se como uma narrativa que articula o estado atual das políticas de educação - orientadas pelo Plano Nacional de Educação (PNE) e pela Base Nacional Comum Curricular-Ensino Médio (BNCC-EM) - com a recente obliteração do ensino de filosofia; os relaciona com os movimentos coletivos, realizados por professores e estudantes de filosofia, na primeira década do século XXI, e as decorrentes conquistas. No interstício entre passado e presente, a narrativa tem em vista mostrar os feitos coletivos referentes a conquistas da filosofia na educação brasileira, a fim de que, no presente que as renega, sejamos capazes de perseverar e criar linhas para sair das situações que aprisionam o pensamento filosófico educacional e o trabalho docente. Uma das linhas propostas e defendida no artigo é a de que os professores das Ciências Humanas e Sociais Aplicadas, especialmente aqueles que têm formação em Filosofia, sejam os responsáveis pelo componente curricular "Projeto de vida", justamente porque é graças à formação filosófica que eles estão melhor habilitados a alcançar os objetivos da proposta do Novo Ensino Médio.

Palavras-chave: BNCC-EM; PNE; Ensino de filosofia; Professor; Projeto de vida.

\begin{abstract}
Based on the figure of the narrator and the type of peasant narrator, the one who saw the story of his land and narrates it, created by Walter Benjamin, the article presents itself as a narrative that articulates the current state of education policies - guided by the National Education Plan (PNE) and the Common National Curriculum Base for High School (BNCC-EM) - with the recent obliteration of the teaching of philosophy; relates them to the collective movements, carried out by philosophy professors and students, in the first decade of the $21 \mathrm{st}$, and the resulting triumphs. In the interstice between past and present, the narrative aims to show the collective achievements related to the conquests of philosophy in Brazilian education, so that, in the present that denies them, we can persevere and create lines to get out of the situations that imprison the educational philosophical thinking and teaching work. One of the lines proposed and defended in the article is that professors of Human sciences and Social applied sciences, especially those with a background in Philosophy, should be responsible for the curricular component "Life project", precisely because it is thanks to their philosophical training, they are better able to achieve the objectives of the New High School proposal. Keywords: BNCC-EM; PNE; Philosophy teaching; Teacher; Life project.
\end{abstract}




\section{Um convite para resistir e perseverar}

Walter Benjamim criou dois tipos ideais que tornam tangível a "figura do narrador": a do marinheiro, que viu terras exóticas e distantes sobre as quais apresenta um relato; e a do camponês, o homem que viu a história de sua terra (1994, p. 198). Ambos, cada um a seu modo, voltam-se para o passado e, com suas narrativas, constituem o presente com elementos do pretérito, mas também o reconstroem desde o presente. Além disso, no jogo entre presente-passado, na medida em que o narrador constitui o presente, é capaz de lamentar a felicidade perdida no passado; sem, no entanto, ficar no lamento, ele alcança a dimensão de uma felicidade possível. Benjamin diz que o registro dessa felicidade possível é realizado na obra literária, uma vez que ela corresponde "às ruínas" das potencialidades não construídas na História, a qual é escrita pela perspectiva triunfante dos vencedores (KOTHE, 1976, p. 42). O narrador da obra literária registra suas histórias, que são ruínas das potencialidades de algo "eventualmente realizável". Ele nos traz restos do que foi ou do que poderia ter sido; testemunha para outros tempos e lugares "indícios de possibilidades em aberto, concretização de um mundo possível, índice de alternativas ao real" (KOTHE, 1976, p. 45).

Apesar de, talvez, o subtítulo do presente artigo sugerir que seu conteúdo é mais um capítulo das disputas de narrativas que há muito vivemos, na, já em curso, era da "pós-verdade"2, não é disso que se trata. Ele é sim uma narrativa que se dirige aos desesperançados e, ao mesmo tempo, teimosos jovens, nascidos no final do século $X X$ e no início do XXI, que eram crianças quando alcançamos conquistas da educação em geral e do ensino de filosofia em especial - teimosos porque insistem em seguir estudando filosofia e apostando na profissão docente; bem como se volta aos colegas de profissão: aos já cansados de lutar e de trabalhar - não sem razão, sobretudo depois do corte de $50 \%$ do tempo da nossa disciplina da grade curricular, tendo que trabalhar em várias escolas e chegar a ter mais de 800 alunos por semana, sem condição alguma para se dedicar a criar suas aulas e inventar a própria docência ${ }^{3}$ - e àqueles que ainda mantêm aceso o ânimo. Trata-se de uma 
narrativa aproximada do sentido dado por Walter Benjamin ao narrador, aquele que conta o que se passou.

Para a composição desta narrativa, realizo um movimento de desterritorialização das ideias de Benjamin, que tratam sobretudo da obra literária, para reterritorializá-las no problemático solo da educação e do ensino de filosofia. Convido os eventuais leitores a lerem-na como o gesto de uma espécie de "narrador camponês" que fala de um passado vivido, espacial e temporalmente, próximo tanto de quem a conta quanto de cada vivente que a lê neste Dossiê. Ademais, convidoos a sentirem, ao fundo da narrativa, o eco de felicidade que, uma vez, foi produzida e testemunhada, a qual indica uma alternativa ao real-atual que parece encerrar o advento de outras possibilidades.

É considerando esse ecoar ainda audível que a inusual palavra "obliteração" compõe o título da narrativa. Se, de um lado, ela é sinônimo de destruição e de eliminação, que vai se dando pouco a pouco, isso não acontece sem deixar vestígios. Então, escrevo como fazem os cães farejadores que encontram vestígios de vida sob escombros e convido os leitores para que assim atuem também, a fim de buscar vida sob ou sobre os "escombros filosóficos". Isso com a intenção de que sejamos capazes de resistir e perseverar em nossa potência de vida, criando linhas para sairmos, coletivamente, das situações que aprisionam o pensamento filosófico educacional e o nosso trabalho docente, porque individualmente não há saída!

\section{Em nome do progresso: arruinamento da educação e do ensino de filosofia}

Em 1921, Walter Benjamin adquiriu o desenho em aquarela Angelus Novus, criado por Paul Klee, no ano anterior. O título desse desenho era para ter sido o nome do projeto benjaminiano de um Jornal que não se materializou; o anjo mensageiro foi apresentado por Benjamin a partir de uma lenda proveniente da tradição hebraica a qual "nos diz que uma legião de anjos novos é criada a cada instante para, depois de entoar seu hino diante de Deus, terminar e dissolver-se no nada" (BENJAMIN apud https://pt.wikipedia.org/wiki/Angelus_Novus). O filósofo deu 
maior notoriedade ao desenho quando o incluiu no texto "Teses sobre a Filosofia da história". Ele compõe a nona tese, que diz o seguinte:

\begin{abstract}
Há um quadro de Klee que se chama Angelus Novus. Representa um anjo que parece querer afastar-se de algo que ele encara fixamente. Seus olhos estão escancarados, sua boca dilatada, suas asas abertas. $O$ anjo da história deve ter esse aspecto. Seu rosto está dirigido para o passado. Onde nós vemos uma cadeia de acontecimentos, ele vê uma catástrofe única, que acumula incansavelmente ruína sobre ruína e as dispersa a nossos pés. Ele gostaria de deter-se para acordar os mortos e juntar os fragmentos. Mas uma tempestade sopra do paraíso e prende-se em suas asas com tanta força que ele não pode mais fechá-las. Essa tempestade o impele irresistivelmente para o futuro, ao qual ele vira as costas, enquanto o amontoado de ruínas cresce até o céu. Essa tempestade é o que chamamos progresso (BENJAMIN, 1994, p. 226).
\end{abstract}

Essa imagem e o sentido atribuído por Benjamim me parecem apropriados para começar a tratar do que, desde o final de 2016, vêm nos chegando como um "pacote" que os educadores em nada, ou quase nada, participaram de sua elaboração, o que se convencionou chamar de "Novo Ensino Médio" (NEM). Documento publicizado, inicialmente, por meio de Medida Provisória ${ }^{4}$ assinada pelo então presidente Michel Temer, dinâmico e atuante colaborador da deposição da presidenta Dilma Rousseff, um dos mentores do golpe contra o sistema democrático que vem sendo tomado de assalto por interesses privados e obscuros desde aquele ano, inclusive no que se refere à educação pública brasileira. Tal educação, diferentemente de agora, seria a "prioridade das prioridades" do governo iniciado em 2015 sob o lema "Brasil, pátria educadora" ${ }^{5}$, uma vez que se orientaria pelo Plano Nacional de Educação (2014-2024), aprovado em um "momento fecundo de possibilidades, com bases legais mais avançadas e com a mobilização estratégica dos setores públicos e de atores sociais importantes neste cenário", com vistas a "realizar um bom trabalho de alinhamento dos planos de educação para fazermos deste próximo decênio um virtuoso marco no destino do nosso País" (BRASIL, 2014, p. 6). O cumprimento das 20 Metas do Plano Nacional de Educação (PNE) seria possível com o expressivo e inédito complemento proveniente da compensação 
financeira pela exploração de petróleo e gás natural ${ }^{6}$. A proposta foi conhecida como o "Passaporte para o futuro", advindo do fundo dos royalties do pré-sal.

Com a interrupção do mandato de Rousseff e o que dela decorreu, desde 2016 até o segundo ano de nossa era pandêmica, em 2021, a educação pública tem investimentos inferiores aos de $2010^{7}$ e, faltando três anos para o final do decênio da vigência do PNE, apenas 5 metas tiveram cumprimento parcial, dentre elas nenhuma é ambiciosa e "nasceram já próximas do cumprimento" ${ }^{8}$. Dadas as poucas ações do atual Ministério da Educação em favor da realização das metas do PNE, a Base Nacional Comum Curricular parece ser o centro do documento norteador das políticas para a educação brasileira, quando, em verdade, é apenas uma dentre as 36 estratégias da Meta $7^{9}$, centrada na qualidade da educação, a qual pretende:

\begin{abstract}
fomentar a qualidade da educação básica em todas as etapas e modalidades, com melhoria do fluxo escolar e da aprendizagem, de modo a atingir as seguintes médias nacionais para o IDEB: 6,0 nos anos iniciais do ensino fundamental; 5,5 nos anos finais do ensino fundamental; 5,2 no ensino médio (BRASIL, 2014, p. 31).
\end{abstract}

Tal qualidade está vinculada, no PNE, também ao estabelecimento de "diretrizes e bases para o seu sistema educacional", o que está ao lado do enfrentamento da desigualdade social, da garantia da "educação como um dos direitos humanos", da "melhoria das condições de trabalho e valorização, formação e desenvolvimento profissional de todos aqueles que atuam na educação" (BRASIL, 2014, p. 32).

As diretrizes e bases indicadas são, justamente, o documento orientador dos planejamentos estaduais, municipais e de cada escola de Educação Básica, assim como das licenciaturas de todo o país, intitulado Base Nacional Comum Curricular. Para o que interessa nesta narrativa, a menção é a versão de 2018, referente ao Ensino Médio (BRASIL, 2018a), propriamente a terceira versão, incomparável às duas anteriores (BRASIL, 2015; 2016), no que se refere à filosofia. No caso do Paraná, a partir desse documento, foi elaborado o "Referencial Curricular para o Ensino Médio", aprovado pelo Pleno do Conselho Estadual de Educação - CEE, em 29 de julho de 2021, a ser implantado no Sistema Estadual de Ensino do Paraná, em 
$2022^{10}$. O Referencial substituirá as "Diretrizes Curriculares do Paraná", construídas com ampla participação, discussão e deliberação dos professores nos primeiros anos do século XXI, processo muito diverso do atual documento que contou, apenas, com duas consultas públicas, uma feita durante as férias docentes, pela Secretaria Estadual de Educação - SEED, e a outra pelo CEE, entre abril e maio, quando os professores estavam se preparando para trabalhar em regime híbrido de ensino, portanto com praticamente nenhuma possibilidade de voltar-se para o documento individual ou coletivamente.

Parece-me que, sem exceção, esses documentos e as políticas estaduais das redes de ensino se apresentam em nome de um "progresso" capaz de atender as demandas atuais da sociedade e dos projetos de vida dos estudantes, que devem ser "protagonistas" de sua formação, a qual, de acordo com a BNCC-EM (2018a, p. 15), implica uma "educação integral" que necessita da "superação da fragmentação radicalmente disciplinar do conhecimento, o estímulo à sua aplicação na vida real, a importância do contexto para dar sentido ao que se aprende e o protagonismo do estudante em sua aprendizagem e na construção de seu projeto de vida".

Suponho que nenhum educador se oponha a isso; no entanto, quando se relaciona o texto da Base com as condições das escolas, da organização dos tempos de aulas e do trabalho docente, da desagregação do que se acostumou chamar de "comunidade escolar", do controle do trabalho docente - por meio de sistemas tecnológicos em rede, monitorados por ameaçadores fiscais, chamados, à boca pequena nas escolas, de "capitães do mato" - o que temos é um "progresso" associado ao que Benjamin, em 1933, vinculou ao avanço técnico ligado ao empobrecimento da experiência. No nosso caso, a experiência do encontro entre o novo e o velho, no sentido arendtiano, que marca justamente a educação como o lugar em que as gerações se encontram e a herança é apresentada e legada para que os novos criem seus projetos de vida a partir dela, rumo ao seu futuro.

Além do anjo da história que apresenta sua mensagem da história humana, pelos olhos arregalados e espantados ${ }^{11}$, e da noção benjaminiana de progresso, cuja marcha precisa ser detida para que ainda consigamos "implodir o enquadramento servil que mantém o status quo" (D'ANGELO, 2019), vou operar 
mais alguns roubos da filosofia de Benjamin - da qual sou uma apreciadora, na condição de "amadora", e não de especialista - para trazer ao nosso território problemático, a fim de pensarmos e atuarmos coletivamente, frente aos escombros e vestígios filosóficos da educação que temos à nossa frente.

\section{Testemunho de um ponto de vista camponês: sobre o que fomos capazes de fazer coletivamente}

Seja como professor ou como estudante, testemunhamos o passado recente que tantas potencialidades produziu para o ensino e a pesquisa filosóficos. Se há um Mestrado Profissional de Filosofia criado em rede nacional (PROF-FILO) ${ }^{12}$, se a disciplina de Filosofia está em todos os currículos do Ensino Médio, se fizemos concursos para trabalharmos com Filosofia na Educação Básica e em Licenciaturas, se produzimos livros e artigos, dissertações e teses específicas acerca do ensino de Filosofia e já temos bons livros didáticos e paradidáticos, tudo isso é porque construímos condições materiais para tais feitos.

E se trata de uma construção com cerca de 20 anos, por isso os escombros ainda não apresentam-se arruinados, os vestígios estão vivos. O trabalho de destruição está no começo, ainda que esteja sendo violento e autoritário. Mas nós, que somos, ao mesmo tempo, testemunhas oculares e criadores dessa construção que vem sendo obliterada, podemos olhar para as condições de efetividade que tornaram possível, e realizada, a felicidade de termos a filosofia efetivada na formação de todo estudante brasileiro e encontrarmos meios para que o processo de espoliação cesse.

Nos anos 90, quando eu fiz graduação, não havia muitas razões para que sequer alimentássemos esperanças de termos a Filosofia nos currículos escolares, como disciplina obrigatória. Eram tempos dos "Temas transversais" e dos Parâmetros curriculares. Mas tímidos movimentos coletivos, aqui e ali pelo Brasil, iniciaram pequenas jogadas, como pedrinhas lançadas em um lago que passaram a criar ondas capazes de ressoar país afora, em diferentes âmbitos. Articulamo-nos entre cursos de Filosofia das mesmas regiões; passamos a fazer eventos 
localizados que, além de criarem estratégias políticas, produziram reflexões, problematizações, teorias para um ensino de filosofia genuinamente brasileiro; convidamos professores da América Latina para partilharem experiências; atraímos deputados e senadores para nossa causa; incluímos questões de filosofia nas provas de vestibulares e, assim, fomos criando necessidades até que, depois de um processo afirmativo no Congresso Nacional e do veto do presidente sociólogo, sem esmorecer, passamos a atuar nas esferas estaduais.

Em 2006, quando as Orientações Curriculares Nacionais de Filosofia foram publicadas, no Paraná, a disciplina foi tornada obrigatória e um processo amplo, participativo e democrático foi produzido para a produção das Diretrizes Curriculares e concursos foram feitos, a fim de garantir pessoal habilitado, no quadro de professores efetivos - o primeiro concurso público estadual do Paraná para professores de Filosofia e Sociologia ocorreu em 2004; assim como noutros estados se deram processos semelhantes; até que, em 2008, foi sancionada lei federal que alterou a LDBEN tornando obrigatórias as disciplinas de filosofia e sociologia. Essa história está narrada em uma Conversa-viagem que aconteceu, em 2008, entre os professores Maurício Langón, do Uruguai, Laura Agratti, da Argentina, Emmanuel Appel, da UFPR, importante articulador político para nossa conquista, e Sílvio Gallo, da UNICAMP, talvez a principal referência nacional para a criação no ensino de filosofia; isso durante a ida ao aeroporto de Porto Alegre, após o "VIII Simpósio SulBrasileiro sobre o ensino de filosofia: filosofia, formação docente e cidadania", ocorrido em Caxias do Sul. Essa conversa foi transcrita por mim e publicada em 2014, na Revista Sul-brasileira de Filosofia e Educação da UNB, a RESAFE ${ }^{13}$. Temos lá uma conversa entre narradores camponeses que testemunharam e fizeram o passado que pode servir para constituirmos o nosso presente.

A partir de 2008, programas nacionais de integração entre universidades e escolas, como o PIBID e o Observatório de Educação, foram criados, o que fomentou a pesquisa teórico-prática em Filosofia e justificou a criação do já referido Mestrado Profissional. O cenário político foi alterado em 2016. A Medida Provisória do Novo EM foi o primeiro golpe explícito contra as humanidades, ao lado da "PEC

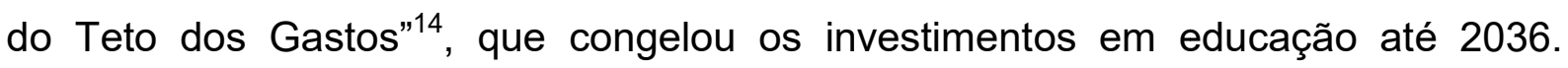


Muitos estudantes reagiram, ocuparam escolas e mostraram sua indignação. No Paraná, a polícia entrou em ação. Por receio e segurança, o movimento se desarticulou, como em outros estados. Apesar da terceira versão da BNCC, que, na prática, obliterou a Filosofia e outras disciplinas da formação dos jovens, houve reações também no Congresso. Há no Senado, desde 2019, um Projeto de Lei aprovado pela Comissão de Educação, faltando ir ao Plenário, de autoria do Senador Romário Faria, do PODEMOS/RJ, que altera o artigo 35 da LDBEN nos seguintes termos:

$\S 2^{\circ} \mathrm{A}$ Base Nacional Comum Curricular referente ao ensino médio incluirá obrigatoriamente estudos e práticas de educação física e artes.

$\S 3^{\circ} \mathrm{O}$ ensino da língua portuguesa, da matemática, da filosofia e da sociologia será obrigatório nos três anos do ensino médio, assegurada às comunidades indígenas, também, a utilização das respectivas línguas maternas.

Nas especificações do relator Romário encontra-se a seguinte redação: "A Sugestão é vazada nos seguintes termos: pela reinserção dos componentes curriculares de Filosofia e Sociologia como componentes obrigatórios do currículo do ensino médio. A proposta visa uma carga horária de 12 períodos distribuídos nos 3 anos letivos" (FARIA, 2019, p. 03, grifos do autor). Na Assembleia Legislativa do Paraná, temos projeto de lei estadual com o mesmo teor no que se refere aos tempos de aulas nos três anos letivos da rede estadual de ensino.

Isso eu narro para relembrarmos que criamos diferentes meios nesses pouco mais de 20 anos, tempo em que criamos história, materiais, articulações, conhecimentos e experiências, em variados sentidos, para que possamos fortalecer nossos constructos e não esmorecer frente à tempestade chamada "progresso". O Angelus Novus de Klee gostaria de acordar os mortos e juntar os fragmentos do passado. Nós não estamos mortos. Embora feridos, alguns desacordados, outros atônitos e imobilizados, olhamos para esse passado que criamos, ao mesmo tempo em que testemunhamos e sabemos que, em primeiro lugar, nada podemos individualmente; em segundo, está claro que, se conseguimos fazer o que fizemos, é porque criamos agenciamentos coletivos com inúmeros companheiros, advindos de diferentes meios; em terceiro, sabemos que é preciso atuar, ao lado da pesquisa e 
do ensino, também politicamente, em esfera macro e micro, como fizemos na primeira década do século XXI.

Ações desse tipo são extremamente coerentes com a sexta competência a ser desenvolvida na Educação Básica, conforme a BNCC-EM: "Participar, pessoal e coletivamente, do debate público de forma consciente e qualificada, respeitando diferentes posições, com vistas a possibilitar escolhas alinhadas ao exercício da cidadania e ao seu projeto de vida, com liberdade, autonomia, consciência crítica e responsabilidade" (BRASIL, 2018a, p. 558). Em quarto lugar, e para logo, podemos atuar por dentro, nos interstícios daquilo que as propostas atuais nos possibilitam, isso porque a educação não é feita de uma só linha em que, em uma ponta estaria o Estado com seus poderes e, na outra, a escola com estudantes e professores, formatados de acordo com aquilo que "vem de cima". Não é assim que as coisas funcionam; há mais linhas no jogo. Como gostava de dizer minha mestra Sandra Corazza, a educação é um "fantástico tear". Tear feito de inúmeras linhas de macro e micropolíticas, de "sonhos da docência", sonhos daqueles que leem-e-escrevem na e para a Aula (CORAZZA, 2021).

\section{O que poderemos para além das aulas de Filosofia, em matilha, com e pela filosofia}

Sobre o que poderemos fazer nos interstícios é que me atenho neste momento da narrativa. Apresentarei alguns elementos presentes na BNCC-EM e em documentos estaduais que estão em elaboração, os quais, em minha perspectiva, não podem se realizar efetivamente sem a filosofia. Isso com vistas a convidar os leitores a acompanhar e atuar em matilha, nos prolongamentos que, espero, poderão advir da leitura desta narrativa, em busca de outros vestígios filosóficos presentes nos novos documentos e políticas para a educação.

Em outras publicações feitas a partir da investigação da BNCC-EM, realizada com a professora de Filosofia, Adriana Muniz Dias, da Rede Estadual do Paraná, foi possível constatar que a Ética é o principal vestígio da Filosofia e que ela ultrapassa a área específica das Ciências Humanas e Sociais Aplicadas, tornando-se uma linha 
orientadora do próprio documento (HEUSER; DIAS, 2020; HEUSER; DIAS, 2021). Ela é uma das dimensões a ser considerada para a "formação e o desenvolvimento humano global" - ao lado das dimensões intelectual, física, afetiva, social, moral, simbólica - e incluída nos currículos a serem construídos a partir da BNCC-EM (BRASIL, 2018a, p. 16). Essas dimensões estão previstas para serem desenvolvidas ao longo da vida escolar, com vistas a "atender às necessidades de formação geral indispensáveis ao exercício da cidadania e responder à diversidade de expectativas dos jovens quanto à sua formação", tal como estabelecido pela Lei de Diretrizes e Bases. Conforme o seu artigo 35, inciso terceiro, a formação ética está associada ao "aprimoramento do educando como pessoa humana" (apud BRASIL, 2018a, p. 464), capaz de "construir e realizar seus projetos de vida, em consonância com os princípios da justiça, da ética e da cidadania” (BRASIL, 2018a, p. 470).

Das "Competências Gerais da Educação Básica”, que são 10, em três a Ética, seus temas e problemas mais diretamente relacionados aparecem: "5. Compreender, utilizar e criar tecnologias digitais de informação e comunicação de forma crítica, significativa, reflexiva e ética"; "6. Fazer escolhas alinhadas ao exercício da cidadania e ao seu projeto de vida, com liberdade, autonomia, consciência crítica e responsabilidade"; "10. Agir [...] com autonomia, responsabilidade, flexibilidade, resiliência e determinação, tomando decisões com base em princípios éticos, democráticos, inclusivos, sustentáveis e solidários" (BRASIL, 2018a, p. 9, 10). Dessas competências gerais, decorrem as específicas, por áreas e suas habilidades.

Pode-se dizer que há duas grandes preocupações que atravessam o documento e requerem, primordialmente, uma formação ética dos estudantes, a saber: as tecnologias digitais de informação e comunicação (TDICs) e a sustentabilidade com consumo responsável. Sem dúvida, esses são problemas do nosso tempo, que se impõem a todos. A filosofia não passa ao largo deles e, como o documento reconhece, ela tem muito a contribuir. Defendemos que a dimensão ética requer uma abordagem filosófica rigorosa, articulada com aquelas duas preocupações principais do documento, e que os profissionais melhor habilitados para tanto são os professores formados em Filosofia. Isso significa que eles têm 
uma função na escola que ultrapassa o escasso tempo designado para as aulas de Filosofia propriamente dita.

O NEM (Novo Ensino Médio) prevê a flexibilização curricular com os "Itinerários formativos" e com o "Projeto de vida" que deverão estar previstos nas políticas educacionais dos estados. Devido à pandemia, os estados brasileiros têm o ano de 2021 para definir esses elementos, mas o Programa Nacional do Livro Didático está impressionantemente adiantado. Já em meados de março de 2021 - muito antes de qualquer secretaria estadual de educação ter finalizado as suas diretrizes curriculares, portanto - todas as escolas já deveriam ter feito suas escolhas e os diretores as registrado no sistema nacional do livro didático, com a possibilidade de a rede de ensino estadual poder "optar" pela "unificação", isto é, escolher "um único material para todas as escolas"15 - coisa que fere a própria BNCC-EM quando afirma "a necessidade de não caracterizar o público dessa etapa [a juventude] como um grupo homogêneo", mas como

[...] condição sócio-histórico-cultural de uma categoria de sujeitos que necessita ser considerada em suas múltiplas dimensões, com especificidades próprias que não estão restritas às dimensões biológica e etária, mas que se encontram articuladas com uma multiplicidade de atravessamentos sociais e culturais, produzindo múltiplas culturas juvenis ou muitas juventudes (BRASIL, 2011, p. 155, apud BRASIL, 2018a, p. 462, 463).

Como poderia um único livro, para um estado inteiro, dar conta de tamanha multiplicidade? Como poderiam os professores escolher os livros mais adequados e coerentes com as diretrizes que sequer estavam concluídas e, menos ainda, eram conhecidas?

Vários elementos que deverão compor o NEM não estão claros na BNCC-EM, como o funcionamento dos "Itinerários formativos" e do "Projeto de vida". No entanto, o Guia $^{16}$ de implementação do NEM, produzido pelo Ministério de Educação dos tempos do presidente Michel Temer, em parceria com o Conselho Nacional dos Secretários Estaduais de Educação e apoiado pelo Fórum Nacional dos Conselhos Estaduais de Educação, orienta o que fazer em cada etapa e indica muitas 
possibilidades para serem adotadas. Esse processo deve considerar três grandes frentes:

o desenvolvimento do protagonismo dos estudantes e de seu projeto de vida, por meio da escolha orientada do que querem estudar; a valorização da aprendizagem, com a ampliação da carga horária de estudos; e a garantia de direitos de aprendizagem comuns a todos os jovens, com a definição do que é essencial nos currículos a partir da BNCC (BRASIL, 2018b, p.3).

Na proposta do Estado do Paraná, o "Projeto de vida" é apresentado como componente curricular para todas as séries do EM; com conteúdos, metodologias e avaliações próprias e, suponho, com professores específicos designados. No final de fevereiro de 2021, a professora da UNIFESP, Dra. Itale Luciane Cericato, fez uma apresentação do que ela concebe por Projeto de Vida. Para ela, se trata do "eixo estruturante do NEM". Na ocasião, contou experiências que realizou na universidade em que trabalha, assim como em escolas ${ }^{17}$. Embora não tenha afirmado que o Projeto de vida deva ser um componente curricular, relatou algumas modalidades possíveis para sua realização, mas defendeu que não pode ser algo que aconteça quando sobra um tempinho da aula, o que é coerente com um "Ponto de Atenção" do Guia:

É importante que seja destinada uma carga horária específica para o desenvolvimento do projeto de vida dos estudantes logo no início da etapa, para que os estudantes tenham a oportunidade de exercer seu protagonismo desde o começo do Ensino Médio, momento em que ocorre o maior número de evasões (BRASIL, 2018b, p.12).

Quanto aos professores responsáveis, ela sugeriu que todos os professores estão aptos, porque a proposta mobiliza conhecimentos de todas as áreas de conhecimento e articula as 10 competências gerais. Ou seja, embora não haja formação específica, é necessário que esses professores reconheçam a importância da elaboração de projetos de vida pelas novas gerações, com o auxílio dos adultos, de forma aberta, democrática e dialogada.

Com as considerações da professora Cericato, e pelas características que o componente curricular ganhou no documento da SEED, defendo que esse 
componente requer, necessariamente, que os docentes responsáveis tenham formação filosófica e, para cumprir alguns objetivos, em Ciências Sociais. Essa defesa não se dá por mero corporativismo, mas pelo teor da proposta. No Guia consta:

\begin{abstract}
DESENVOLVIMENTO DO PROJETO DE VIDA DOS ESTUDANTES: considerando as Competências Gerais da BNCC e a LDB, as redes deverão definir estratégias para trabalhar o desenvolvimento do projeto de vida dos estudantes, como orientação vocacional e profissional e preparação para o mundo do trabalho, atividades para trabalhar a capacidade dos estudantes de definirem objetivos para sua vida pessoal, acadêmica, profissional e cidadã, de se organizarem para alcançar suas metas, de exercitarem determinação, perseverança e autoconfiança para realizar seus projetos presentes e futuros. Este também pode ser um espaço importante para ajudar os estudantes na escolha de seus itinerários formativos (BRASIL, 2018b, p. 23).
\end{abstract}

Vejamos o caso do Paraná, em que o componente funcionará por meio de "grupos de diálogos" com "escuta ativa" nos quais "os(as) jovens irão elaborar seus projetos de vida, centrados nas expectativas de escolarização e do mundo do trabalho" (PARANÁ, 2021, p. 12); a partir do que o documento chama de "objetos de conhecimento", que são: 1) Identidade e Diferença; 2) Valores; 3) Ética e Cidadania; 4) Aprendendo a ser e conviver (esses na $1^{\text {a }}$ série); 5) Juventude, sonhos e planejamento; 6) Elementos do Projeto de Vida (2a série); 7) Qualificação do Projeto de Vida; e 8) Avaliação do Projeto de Vida ( $3^{a}$ série). Tais objetos de conhecimento estão praticamente todos vinculados a habilidades da área de Ciências Humanas e Sociais Aplicadas, o que pode ser verificado nas especificações da tabela. 
Tabela 1 - $1^{\text {a }}$ Série: Unidade Curricular: Aprendendo a Ser e Conviver

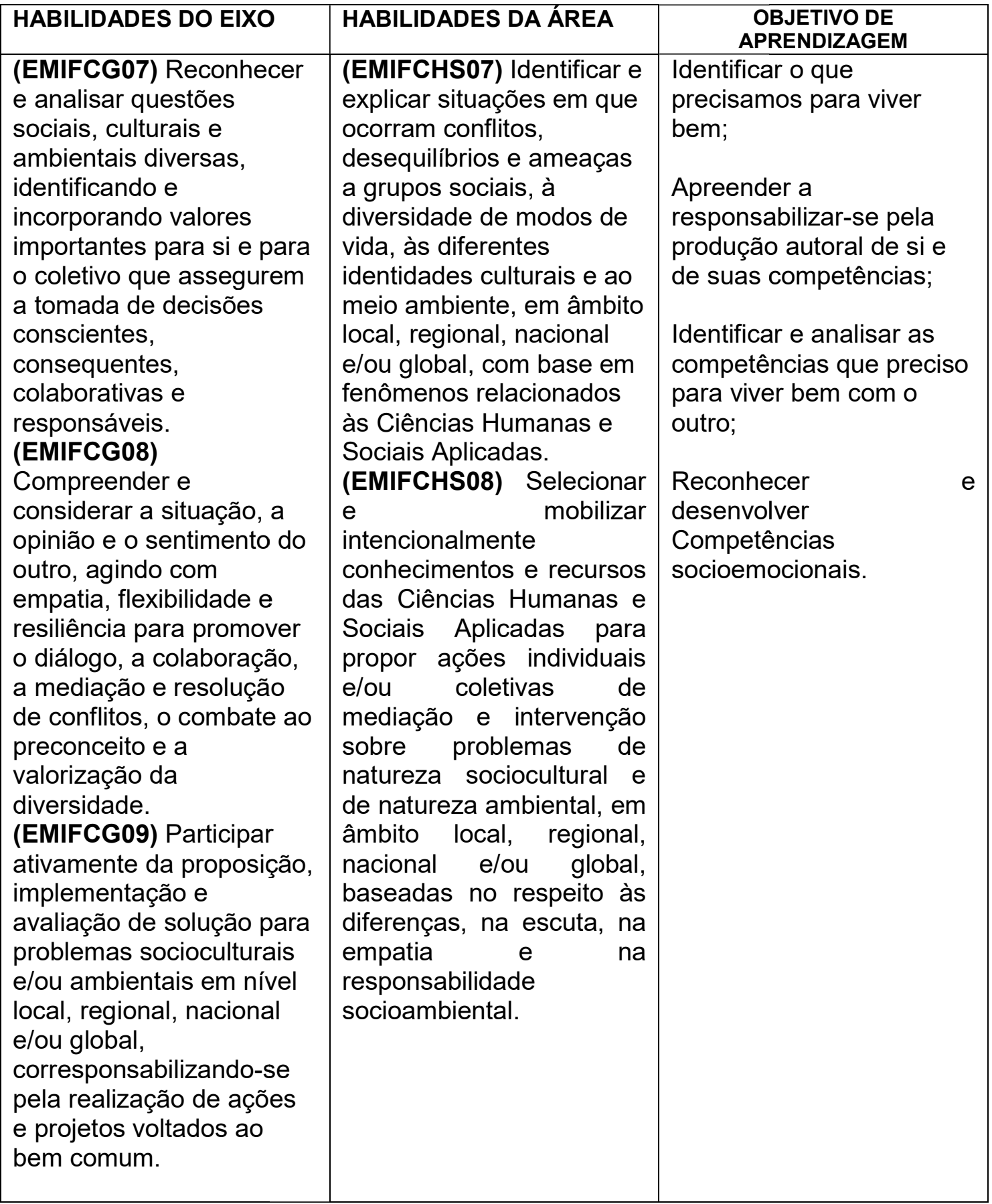

Fonte: Referencial Curricular para o Novo Ensino Médio Paranaense - versão preliminar 2: componente de Projeto de Vida, 2021.

É próprio das Licenciaturas de humanidades tratarem de problemas referentes às temáticas que constituem a razão de ser do "Projeto de vida", assim como as 
metodologias que muitos de nós utilizamos e criamos para a formação de professores. Por essas razões, penso que podemos, por dever de ofício, atuar junto aos estados para que neste componente curricular nós, das Ciências Humanas e Sociais Aplicadas, tenhamos prioridade.

Embora vivamos tempos de quase nenhum diálogo, justamente graças às concepções políticas de grande parte dos grupos que ocupam as pastas que vêm deliberando os formatos do NEM, o qual afirma a necessidade da formação das juventudes pautada no diálogo, no protagonismo e em processos democráticos, temos razões e argumentos de sobra para afirmar e mostrar que, sem a Filosofia e uma postura filosófica cultivada nas escolas, a "novidade" não se realizará. Mas também avalio que as ideias desses documentos todos só se efetivarão, perderão sua abstração, ganhando concretude no chão da escola se, e somente se, a estrutura material das escolas for alterada, garantindo espaços físicos para que os grupos de diálogo se encontrem; assim como a lógica de distribuição dos tempos das aulas e de trabalho dos professores mude. É incompatível que professores acompanhem as juventudes, nas comunidades escolares, com o tempo de trabalho fragmentado em várias escolas. Por essa razão, é preciso retomar todas as metas do PNE e suas estratégias, trazendo para o centro do debate público do país os problemas da Educação. Ainda temos um triênio para isso. Para encerrar esta narrativa, trago outra imagem de anjos, agora kafkiana.

\footnotetext{
Ele tem dois inimigos: o primeiro ameaça-o por trás, desde as origens; o segundo fecha-lhe o caminho para diante. Luta contra ambos. Na realidade, o primeiro apoia-o em sua luta contra o segundo, quer impeli-lo para diante e da mesma maneira o segundo o apoia em sua luta contra o primeiro, empurra-o para trás. Mas isso é assim só teoricamente. Porque além de adversários também existe ele, e quem conhece suas intenções? Seu sonho é que, em um momento de descuido - e isso exigiria uma noite mais escura do que jamais o foi nenhuma noite - possa saltar fora da linha de combate e ser alçado, por conta da sua experiência de luta, por cima dos combatentes, como árbitro (KAFKA, apud ARENDT, 2000, p. 33, com adaptações).
}

Considerando o nosso território filosófico-educacional, a mim a imagem sugere que a personagem "Ele" pode ser nós, docentes, que estamos em meio à disputa de projetos e (anti)projetos de Educação pública. A nós eu proponho uma questão a ser 
respondida coletivamente: e se juntos atuarmos como árbitros da educação, para que cessem as políticas de obliteração do ensino de filosofia, mas também daquilo que realmente importa em educação, a criação coletiva de sonhos realizáveis, o que poderá uma docência assim? Temos experiências exitosas de luta. Já saltamos por cima dos combatentes que queriam o nosso aniquilamento e fomos vencedores. Podemos criar outros possíveis a serem narrados por nós e pelos que estão chegando.

\section{Referências}

ARENDT, Hannah. Entre o passado e o futuro. Tradução de Mauro W. Barbosa. São Paulo: Perspectiva, 2000.

BAPTISTA, Mauro Rocha. Sobre anjos e folhas secas: em torno do Angelus Novus de Paul Klee. Revista Horizonte, v. 7, n. 13, p. 127-141, dez. 2008.

BENJAMIN, Walter. Obras Escolhidas, v. I, Magia e técnica, arte e política: ensaios sobre literatura e história da cultura. 7. ed. Tradução de Sérgio Paulo Rouanet. São Paulo: Brasiliense, 1994.

BRASIL, Ministério da Educação. Planejando a Próxima Década: conhecendo as 20 metas do Plano Nacional de Educação. Brasília: MEC, Secretaria de Articulação com os Sistemas de Ensino, 2014.

BRASIL, Ministério da Educação. Base Nacional Comum Curricular. Brasília: MEC, SEB, 2015.

BRASIL, Ministério da Educação. Base Nacional Comum Curricular: $2^{\mathrm{a}}$ versão revista. Brasília: MEC, SEB, 2016.

BRASIL, Ministério da Educação. Base Nacional Comum Curricular. Brasília: MEC, SEB, 2018a.

BRASIL, Ministério da Educação. Guia de implementação do Novo Ensino Médio. Brasília: MEC, CONSED, 2018b.

CORAZZA, Sandra Mara. O sonho da docência: fantástico tear. Revista Proposições, Campinas, SP, v. 32, 2021. Disponível em https://www.scielo.br/j/pp/a/kZHMS9MfhZR3GRgrqqjFBXN/. Acesso em 30 ago. 2021. 
D'ÂNGELO, Martha. Walter Benjamin, crítica da cultura e do progresso. Revista Cult, n. 245. Disponível em: https://revistacult.uol.com.br/home/walter-benjamincultura-progresso/. Acesso em 12 mar. 2021.

FARIA, Romário. Projeto de Lei No 2579, de 2019. Brasília: Senado Federal, 2019.

HEUSER, Ester Maria Dreher; DIAS, Adriana Muniz. Raspas e restos de Filosofia na BNCC-EM: trampolim para uma ética como experimentação. Revista Teias, Rio de Janeiro, RJ, v. 21, n. 63, 2021. Disponível em https://www.epublicacoes.uerj.br/index.php/revistateias/article/view/53280. Acesso em 30 ago. 2021.

HEUSER, Ester Maria Dreher; DIAS, Adriana Muniz. Espólios filosóficos na Base Nacional Comum Curricular-Ensino Médio: a dimensão ética. Revista Conjectura: filosofia e educação, Caxias do Sul, RS, v. 26, 2021. Disponível em http://www.ucs.br/etc/revistas/index.php/conjectura/article/view/9017/pdf. Acesso em 19 out. 2021.

KOTHE, F.R. Para ler Benjamin. Rio de Janeiro: Francisco Alves, 1976.

\section{PARANÁ. Referencial Curricular para o Novo Ensino Médio Paranaense - versão preliminar 2: componente de Projeto de Vida. Curitiba: Sistema Estadual de Ensino do Paraná, 2021.}

\section{Notas}

1 Este artigo foi produzido a partir da aula inaugural do Mestrado Profissional em Filosofia da UNIMONTES (Universidade Estadual de Montes Claros - MG), em 25 de março de 2021, intitulada "Escombros filosóficos: BNCC-EM, diretrizes curriculares e as políticas de obliteração do ensino de filosofia". A aula está disponível em: https://www.youtube.com/watch?v=BCWJgoMI5OY.

2 Em 2016, o Dicionário Oxford escolheu a palavra "pos-truth" como a palavra do ano, decorrente do Referendo britânico pela saída ou não da Comunidade Europeia, o BREXIT, as eleições de Donald Trump, como presidente dos Estados Unidos e a frequência do termo em análises políticas, que se tornou cada vez mais comum, desde aquele ano, e se intensificou na pandemia, atingindo o âmbito das ciências e das (des)orientações relativas aos cuidados e tratamentos da COVID-19. Disponível em: https://languages.oup.com/word-of-the-year/2016/. Acesso em 09 ago. 2021. Oswaldo Giacoia, em 2018, fez uma análise sobre o tema e o relacionou com as perspectivas nietzschiana e foucaultiana. Disponível em: E se o erro, a fabulação, o engano revelarem-se tão essenciais quanto a verdade? - Laboratório de Sensibilidades (wordpress.com). Acesso em 09 ago. 2021. Introduzo esta nota para evidenciar que a Filosofia tem uma função que só ela pode cumprir neste século, em termos de formação para lidar com as novas tecnologias da informação e da comunicação (TDICs), e que ela não pode ser negligenciada na escola, caso realmente a quinta Competência Geral da BNCC seja contemplada, a saber: "5.Compreender, utilizar e criar tecnologias digitais de informação e comunicação de forma crítica, significativa, reflexiva e ética nas diversas práticas sociais (incluindo as escolares) para se comunicar, acessar e disseminar informações, produzir conhecimentos, resolver problemas e exercer protagonismo e autoria na vida pessoal e coletiva" (BRASIL, 2018a, p. 09). 
${ }^{3}$ Essa é a situação atual dos professores no Estado do Paraná, onde trabalho com formação de professores de Filosofia na Universidade Estadual do Oeste do Paraná - UNIOESTE. Hoje, um professor de filosofia, com contrato de trabalho de 40 horas semanais, atende entre 28 e 30 turmas, muitos em até 7 escolas. Enquanto escrevo este texto, os professores estão em regime híbrido de trabalho, com dez alunos presentes em sala, na escola, e os demais sendo atendidos via plataforma virtual. Como se esse quadro, semelhante a um delírio coletivo e distópico sem fim, não bastasse, os professores precisam alimentar, diariamente, o sistema informatizado de Registro de Classe On-line e seguir os conteúdos pré-determinados pela Secretaria Estadual de Educação, que devem ser cumpridos na ordem e a cada aula, o que acaba reduzindo as possibilidades de um trabalho autônomo e criativo dos professores de todas as disciplinas. Isso justamente quando a lei do Novo Ensino Médio quer ampliar a autonomia dos estudantes, assim como "flexibilizar" o ensino, mas, contraditoriamente, quase acaba com toda a flexibilidade do trabalho docente - digo "quase" porque, em tese, a metodologia ainda será escolha de cada professor.

4 Disponível em: https://www.congressonacional.leg.br/materias/medidas-provisorias/-/mpv/126992. Acesso em 29 ago. 2021.

5 Disponível em: https://www.camara.leg.br/noticias/448217-integra-do-discurso-de-posse-dapresidente-dilma-rousseff-no-congresso/. Acesso em 29 ago. 2021.

${ }^{6}$ Disponível em: http://www.planalto.gov.br/ccivil_03/_ato2011-2014/2013/lei//12858.htm. Acesso em 29 ago. 2021.

${ }^{7}$ Disponível em: https://br.noticias.yahoo.com/com-menor-orcamento-do-mec-na-decada-brasil-podeviver-apagao-na-educacao-em-2021-

070002673.html?guccounter=1\&guce_referrer=aHR0cHM6Ly93d3cuZ29vZ2xILmNvbS8\&guce_referr er_sig=AQAAAA6n_Ei017wBKhqrY-

gNy3JOG2aGgL6_yR1fAEfCUolahmxGhco6LEx1VdyhmBtPymgw_LvnFC7IJWinS6z-

f3a7sWu_elhsLMOIdR2UrA_PShi3GMe0n7btg1mhBUulqPmflW22tH-

To_k3gn5 GpfHpAh4J0IYHm11vkDOJC9tQR. Acesso em 29 ago. 2021.

${ }^{8}$ Disponível em: https://campanha.org.br/noticias/2021/06/24/por-mais-um-ano-grande-maioria-dosdispositivos-de-metas-do-plano-nacional-de-educacao-nao-devem-ser-cumpridos-no-prazo-indicabalanco/. Acesso em 29 ago. 2021.

${ }^{9}$ Estratégia 7.1) "estabelecer e implantar, mediante pactuação interfederativa, diretrizes pedagógicas para a educação básica e a base nacional comum dos currículos, com direitos e objetivos de aprendizagem e desenvolvimento dos (as) alunos (as) para cada ano do ensino fundamental e médio, respeitada a diversidade regional, estadual e local". Disponível em: https://novaescola.org.br/conteudo/3003/pne-meta-7. Acesso em 30 ago. 2021.

${ }^{10}$ Disponível em: http://www.cee.pr.gov.br/Noticia/CEEPR-aprova-Deliberacao-que-institui-DiretrizesCurriculares-Complementares-e-o.Acesso em 30 ago. 2021.

${ }^{11}$ Para Baptista (2008, p. 132), o que o Angelus Novus faz é anunciar a vigência do estado de exceção, o que, nas devidas proporções, parece se avizinhar das circunstâncias do país quando finalizo esta narrativa, período em que estão sendo chamadas, por policiais militares e outros setores da sociedade, manifestações contra o Supremo Federal Superior, em 7 de setembro de 2021.

12 Informações sobre este projeto integrado em 17 regiões do país disponíveis no site da ANPOF: http://www.anpof.org/portal/index.php/en/artigos-em-destaque/1126-marilena-chaui-ministrara-aulainaugural-do-prof-filo. Acesso em 30 ago. 2021. 
13 Disponível em: https://periodicos.unb.br/index.php/resafe/article/view/4644. Acesso em $10 \mathrm{mar}$. 2021.

14 Disponível em: https://www12.senado.leg.br/noticias/materias/2016/12/15/promulgada-emendaconstitucional-do-teto-de-gastos. Acesso em 30 ago. 2021.

15 Cf. https://www.gov.br/fnde/pt-br/acesso-a-informacao/acoes-e-programas/programas/programasdo-livro/pnld/informes-

pnld/2021/10.2021ComeouaEscolhadoPNLD2021Objeto1ProjetosIntegradoreseProjetodeVida.pdf. Acesso em 16 mar. 2021.

16 Disponível em: http://novoensinomedio.mec.gov.br/resources/downloads/pdf/Guia.pdf. Acesso em 10 mar. 2021.

${ }^{17}$ A exposição aconteceu como atividade de formação continuada da SEED/PR e está disponível em: https://www.youtube.com/watch?v=b6pEw0cm9eUAcesso em 12 de mar. 2021.

\section{(c) (1) (8)(2)}

This work is licensed under a Creative Commons Attribution-NonCommercial 4.0 International (CC BY-NC 4.0) 